\title{
Cognitive composites for genetic frontotemporal dementia: GENFI-Cog
}

Jackie M. Poos 1,2, Katrina M. Moore², Jennifer Nicholas³, Lucy L. Russell², Georgia Peakman², Rhian S. Convery², Lize C. Jiskoot ${ }^{1,2}$, Emma van der Ende1, Esther van den Berg ${ }^{1}$, Janne M. Papma ${ }^{1}$, Harro Seelaar ${ }^{1}$, Yolande A. L. Pijnenburg ${ }^{4}$, Fermin Moreno ${ }^{5}$, Raquel Sanchez-Valle ${ }^{6}$, Barbara Borroni ${ }^{7}$, Robert Laforce ${ }^{8}$, Mario Masellis ${ }^{9}$, Carmela Tartaglia ${ }^{10}$, Caroline Graff ${ }^{11}$, Daniela Galimberti ${ }^{12,13}$, James B. Rowe ${ }^{14}$, Elizabeth Finger ${ }^{15}$, Matthis Synofzik ${ }^{16,17}$, Rik Vandenberghe ${ }^{18}$, Alexandre de Mendonça ${ }^{19}$, Pietro Tiraboschi ${ }^{20}$, Isabel Santana ${ }^{21}$, Simon Ducharme ${ }^{22}$, Chris Butler ${ }^{23}$, Alexander Gerhard ${ }^{24}$, Johannes Levin 25,26,27, Adrian Danek ${ }^{25}$, Markus Otto ${ }^{28}$, Isabel Le Ber $29,30,31$, Florence Pasquier ${ }^{32,33,34}$, John C. van Swieten ${ }^{1}$, Jonathan D. Rohrer ${ }^{2^{*}}$ (D) and on behalf of the Genetic FTD Initiative (GENFI)

\begin{abstract}
Background: Clinical endpoints for upcoming therapeutic trials in frontotemporal dementia (FTD) are increasingly urgent. Cognitive composite scores are often used as endpoints but are lacking in genetic FTD. We aimed to create cognitive composite scores for genetic frontotemporal dementia (FTD) as well as recommendations for recruitment and duration in clinical trial design.
\end{abstract}

Methods: A standardized neuropsychological test battery covering six cognitive domains was completed by 69 C9orf72, 41 GRN, and 28 MAPT mutation carriers with CDR ${ }^{\circledR}$ plus NACC-FTLD $\geq 0.5$ and 275 controls. Logistic regression was used to identify the combination of tests that distinguished best between each mutation carrier group and controls. The composite scores were calculated from the weighted averages of test scores in the models based on the regression coefficients. Sample size estimates were calculated for individual cognitive tests and composites in a theoretical trial aimed at preventing progression from a prodromal stage (CDR ${ }^{\circledR}$ plus NACC-FTLD 0.5) to a fully symptomatic stage (CDR ${ }^{\circledR}$ plus NACC-FTLD $\left.\geq 1\right)$. Time-to-event analysis was performed to determine how quickly mutation carriers progressed from $C D R^{\circledR}$ plus NACC-FTLD $=0.5$ to $\geq 1$ (and therefore how long a trial would need to be).

Results: The results from the logistic regression analyses resulted in different composite scores for each mutation carrier group (i.e. C9orf72, GRN, and MAPT). The estimated sample size to detect a treatment effect was lower for composite scores than for most individual tests. A Kaplan-Meier curve showed that after 3 years, $\sim 50 \%$ of individuals had converted from CDR ${ }^{\circledR}$ plus NACC-FTLD 0.5 to $\geq 1$, which means that the estimated effect size needs to be halved in sample size calculations as only half of the mutation carriers would be expected to progress from CDR ${ }^{\circledR}$ plus NACC FTLD 0.5 to $\geq 1$ without treatment over that time period.

Discussion: We created gene-specific cognitive composite scores for C9orf72, GRN, and MAPT mutation carriers, which resulted in substantially lower estimated sample sizes to detect a treatment effect than the individual cognitive

\footnotetext{
${ }^{*}$ Correspondence: j.rohrer@ucl.ac.uk

${ }^{2}$ Dementia Research Centre, Department of Neurodegenerative Disease,

National Hospital for Neurology and Neurosurgery, UCL Institute of Neurology, 8-11 Queen Square, Box 16, London WC1N 3BG, UK Full list of author information is available at the end of the article
}

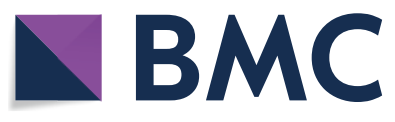

(c) The Author(s) 2022. Open Access This article is licensed under a Creative Commons Attribution 4.0 International License, which permits use, sharing, adaptation, distribution and reproduction in any medium or format, as long as you give appropriate credit to the original author(s) and the source, provide a link to the Creative Commons licence, and indicate if changes were made. The images or other third party material in this article are included in the article's Creative Commons licence, unless indicated otherwise in a credit line to the material. If material is not included in the article's Creative Commons licence and your intended use is not permitted by statutory regulation or exceeds the permitted use, you will need to obtain permission directly from the copyright holder. To view a copy of this licence, visit http://creativecommons.org/licenses/by/4.0/. The Creative Commons Public Domain Dedication waiver (http://creativeco mmons.org/publicdomain/zero/1.0/) applies to the data made available in this article, unless otherwise stated in a credit line to the data. 
tests. The GENFI-Cog composites have potential as cognitive endpoints for upcoming clinical trials. The results from this study provide recommendations for estimating sample size and trial duration.

Keywords: Frontotemporal dementia, Cognition, Neuropsychology, Composite score, Language, Attention, Executive function, Memory, Social cognition

\section{Background}

Frontotemporal dementia (FTD) encompasses a heterogeneous group of early-onset neurodegenerative disorders caused by prominent frontal and/or temporal lobe degeneration with a wide range of overlapping clinical features [1]. The two main phenotypes are behavioural variant FTD (bvFTD), with prominent behavioural changes and executive dysfunction [2], and primary progressive aphasia (PPA), with impairment in language comprehension and/or production [3]. FTD is a highly heritable disease, with $20-30 \%$ of cases having an autosomal dominant pattern of inheritance [4]. The most common causes of genetic FTD are mutations in the microtubule-associated protein tau (MAPT), progranulin $(G R N)$, and chromosome 9 open reading frame 72 (C9orf72) genes [4].

Clinical trials testing disease-modifying treatments for FTD are now underway, and clinical endpoints to monitor treatment response are therefore urgently needed. It is believed that interventions may have the most profound effect if initiated in the earliest stages of the disease; however, a major challenge facing these clinical trials is the lack of outcome measures that are sensitive enough to track the effects of treatment in the early stages of the disease [5-7].

Traditional outcomes such as progression to clinical diagnosis or cognitive measures developed for other forms of dementia such as Alzheimer's disease (AD) might not be well-suited to serve as endpoints for earlystage FTD treatment trials because of the large sample size and long trial duration that would be required to measure possible treatment effects or due to the psychometric properties of the tests themselves [8-10]. Sensitive outcome measures in patients with clinically diagnosed AD, such as the Alzheimer's Disease Assessment Scale Cognitive Subscale (ADAS-Cog), might not be sensitive to decline in patients with FTD $[10,11]$. Multiple genetic FTD cohort studies have investigated a wide range of cognitive instruments and found genespecific cognitive impairment and/or decline in language, executive function, social cognition, attention/processing speed, and memory, in symptomatic and presymptomatic stages [12-27]. However, due to the subtlety of cognitive decline in the early stages of the disease, using individual tests as outcome measures might not be sensitive enough to detect a treatment effect. Furthermore, an individual cognitive test is limited to measuring only one specific symptom, and due to the heterogeneity of clinical features between FTD patients, tests from multiple cognitive domains would need to be included. A selection of the most sensitive tests for each genetic group would enable shortening of the neuropsychological test battery thereby significantly minimizing time and other resource costs compared to using a broad range of individual cognitive tests [28].

Composite scores are often used in clinical trials to reduce the number of variables used as outcome measures [8]. A composite score is any measure which combines the results of multiple cognitive and clinical assessments into a single summary score [29]. As a result, it provides a measure of multiple domains but can serve as a single primary endpoint in clinical trials [8]. Such composites have been developed for several neurodegenerative disorders, such as AD (e.g. the ADAS-Cog [11]), Parkinson's disease (PD) (e.g. the Unified Parkinson's Disease Rating Scale (UPDRS) [30]), and Huntington's disease (HD) (e.g. the Unified Huntington's Disease Rating Scale (UHDRS) [29]) but are, as of yet, lacking in FTD.

Therefore, the aim of this study was to create genespecific cognitive composite scores for $M A P T, G R N$, and C9orf72 mutation carriers in the early symptomatic stage by empirically determining the combination of neuropsychological tests most sensitive to differentiate mutation carriers from non-carriers. Data was collected within the Genetic FTD Initiative (GENFI), an international genetic FTD cohort study aimed at developing novel markers of disease onset and progression [14]. To evaluate their performance, we compared the sample size requirements between each of the proposed composites and individual cognitive tests for a theoretical trial aimed at preventing progression from a prodromal stage $\left(\mathrm{CDR}^{\circledR}\right.$ plus NACCFTLD $[31]=0.5)$ to a fully symptomatic stage $\left(\mathrm{CDR}^{\circledR}\right.$ plus NACC-FTLD $\geq 1$ ). Lastly, we performed time-toevent analyses to determine how many people progressed from a CDR ${ }^{\circledR}$ plus NACC FTLD 0.5 to $\geq 1$, to provide recommendations on the duration of such clinical trials.

\section{Methods}

\section{Participants}

Data was included from the fifth GENFI data freeze in which participants from confirmed genetic FTD families were recruited between 30 January 2012 and 31 
May 2019 in 24 centres across Europe and Canada. A total of 69 C9orf72, $41 \mathrm{GRN}$, and 28 MAPT mutation carriers with a CDR ${ }^{\circledR}$ plus NACC FTLD $\geq 0.5$ and 275 mutation-negative controls (i.e. family members who tested negative for the mutation) were included in this study. Of the mutation carrier group, 41 C9orf72, 17 $G R N$, and $16 M A P T$ mutation carriers fulfilled the diagnostic criteria for bvFTD [2] (C9orf72 $=36, G R N=11$, $M A P T=16)$, PPA [3] $(G R N=6)$, or FTD with amyotrophic lateral sclerosis (FTD-ALS) [32] $($ C9orf72 = 5). Participant characteristics are summarized in Table 1 , and the number of participants included in each of the statistical analysis steps can be found in Fig. S1.

\section{Procedure}

All participants completed a comprehensive neuropsychological test battery covering six cognitive domains: language (modified Camel and Cactus Test [33]; Boston Naming Test (BNT, short 30 item version) [34]; category fluency (animals) [35]), attention/processing speed and executive function (WMS-R Digit span [34]; Trail Making Test (TMT) [36]; WAIS-R Digit Symbol test [34]; D-KEFS Colour-Word Interference Test (CWIT) [37];

Table 1 Participant characteristics and neuropsychological test results

\begin{tabular}{|c|c|c|c|c|}
\hline & C9orf72 & GRN & MAPT & Controls \\
\hline Number of participants & 69 & 41 & 28 & 275 \\
\hline Sex, f:m & $30: 39$ & $20: 21$ & $14: 14$ & 160:115 \\
\hline Age & $55(12.0)$ & $53.0(11.4)$ & $51.1(12.6)$ & $45.8(12.7)$ \\
\hline Education & $13.7(3.1)$ & $14.0(3.5)$ & $14.3(3.4)$ & $14.6(3.4)$ \\
\hline MMSE & $27.1(3.2)$ & $26.6(7.0)$ & $27.5(3.0)$ & $29.3(2.1)$ \\
\hline CDR $^{\circledR}$ plus NACC FTLD sob & $5.9(5.5)$ & $3.4(4.8)$ & $4.8(5.0)$ & $0.2(0.6)$ \\
\hline \multicolumn{5}{|l|}{ Language } \\
\hline Camel and Cactus Test & $-1.81(2.81)$ & $-0.57(1.36)$ & $-2.10(3.08)$ & - \\
\hline Boston Naming Test & $-1.77(3.32)$ & $-0.68(1.62)$ & $-2.63(3.16)$ & - \\
\hline Category fluency & $-1.20(1.05)$ & $-0.54(1.04)$ & $-0.84(1.14)$ & - \\
\hline \multicolumn{5}{|l|}{ Attention and mental processing speed } \\
\hline Digit span forward & $-0.39(1.19)$ & $-0.08(1.26)$ & $0.13(1.23)$ & - \\
\hline Trail Making Test - part A & $-1.37(2.17)$ & $-0.69(1.63)$ & $-0.72(1.54)$ & - \\
\hline Digit symbol & $-1.18(1.30)$ & $-0.62(1.23)$ & $-0.67(1.31)$ & - \\
\hline D-KEFS CWIT - colour naming & $-2.85(3.58)$ & $-0.52(1.85)$ & $-1.30(2.17)$ & - \\
\hline D-KEFS CWIT - word naming & $-1.86(3.11)$ & $-0.02(1.46)$ & $-0.54(1.47)$ & - \\
\hline \multicolumn{5}{|l|}{ Executive function } \\
\hline Digit span backward & $-0.53(1.23)$ & $-0.49(1.23)$ & $-0.19(0.98)$ & - \\
\hline Trail Making Test - part B & $-2.44(2.95)$ & $-1.81(3.06)$ & $-1.37(2.58)$ & - \\
\hline D-KEFS CWIT - ink naming & $-3.46(3.91)$ & $-1.13(2.21)$ & $-1.16(2.54)$ & - \\
\hline Phonemic fluency & $-1.18(1.18)$ & $-0.08(1.33)$ & $-0.64(1.28)$ & - \\
\hline \multicolumn{5}{|l|}{ Visuoconstruction } \\
\hline Benson figure copy & $-0.90(1.90)$ & $-0.06(1.16)$ & $-0.46(1.39)$ & - \\
\hline \multicolumn{5}{|l|}{ Memory } \\
\hline Benson figure recall & $-0.72(1.57)$ & $-0.75(1.46)$ & $-1.27(1.91)$ & - \\
\hline FCSRT free recall & $-1.68(1.36)$ & $-0.72(1.49)$ & $-1.71(1.80)$ & - \\
\hline FCSRT total recall & $-2.20(3.56)$ & $-1.42(3.05)$ & $-2.86(3.62)$ & - \\
\hline FCSRT delayed free recall & $-1.59(1.59)$ & $-0.97(1.58)$ & $-1.72(2.04)$ & - \\
\hline FCSRT delayed total recall & $-2.10(3.81)$ & $-1.13(3.09)$ & $-2.82(4.02)$ & - \\
\hline \multicolumn{5}{|l|}{ Social cognition } \\
\hline Facial Emotion Recognition Test & $-1.67(1.87)$ & $-1.00(1.47)$ & $-1.04(1.59)$ & - \\
\hline
\end{tabular}

Values are mean Z-scores (raw score - mean score controls/standard deviation of controls) corrected for age, years of education, and sex, with standard deviation in parentheses unless otherwise specified. For the FCSRT and letter fluency, an additional correction was made for language as stimuli differed between languages Abbreviations: C9orf72 chromosome 9 open reading frame 72, GRN progranulin, MAPT microtubule-associated protein tau, MMSE Mini-Mental State Examination, $C D R^{\circledast}$ plus NACC FTLD sob Clinical Dementia Rating scale plus National Alzheimer's Coordinating Center Frontotemporal Lobar Degeneration sum of boxes, D-KEFS CWIT Delis-Kaplan Executive Function System Colour-Word Interference Test, FCSRT Free and Cued Selective Reminding Test 
phonemic fluency [35]), verbal and visuospatial memory (Free and Cued Selective Reminding Test (FCSRT) [20]; Benson figure recall), social cognition (Facial Emotion Recognition test [38]), and visuoconstruction (Benson figure copy). The Mini-Mental State Examination (MMSE) [39] was administered to measure global cognitive functioning, and clinical status was determined by means of a structured clinical interview, including the $\mathrm{CDR}^{\circledR}$ plus NACC FTLD [31].

\section{Statistical methods}

Statistical analyses were performed using Stata version 14 and $\mathrm{R}$ version 3.6.2. We compared the continuous demographic data between the mutation carrier groups with Kruskal-Wallis and post hoc Mann-Whitney tests. A chisquare test was used to compare sex between the groups.

All neuropsychological data were converted to $Z$-scores corrected for age, education, and sex compared to the control group collected within GENFI (i.e. mutation-negative participants). The FCSRT and letter fluency scores were also corrected for language as the test stimuli differed by language across the different GENFI sites. The control data available in each language can be found in Additional file 1: Table S1. $Z$-scores for tests with reaction times (i.e. TMT and D-KEFS CWIT) were inversed so that lower $Z$-scores indicated worse performance on all tests. A detailed description of how the corrected $Z$-scores were calculated can be found in Additional file 1.

\section{Creating the composite scores}

Least absolute shrinkage and selection operator (LASSO) [40] logistic regression models with 10-fold cross-validation were used to identify the combination of neuropsychological tests that discriminated best between each mutation carrier group and controls. Participants with missing data were excluded from this analysis. A separate model was fitted for each genetic group with carrier status as the outcome and the neuropsychological tests as the predictors. A detailed description of the statistical methods can be found in Additional file 1. The glmnet package in $\mathrm{R}$ was used to fit the LASSO models and carry out the cross-validation.

From the resulting model, two different cognitive composite scores were calculated: (1) an average of the scores for all cognitive tests that were selected in the model and (2) a weighted average of the scores for all cognitive tests that were selected in the model, using the regression coefficients to determine the weights.

\section{Sample size calculation}

For each outcome, the sample size was calculated for a hypothetical two-arm study with 1:1 randomization to placebo versus active drug with $80 \%$ power to detect a treatment effect at a 5\% significance level [41]. The focus of future studies is likely to be on treating people with very early symptomatic disease, and so, we focused on calculating the sample sizes for a trial of prodromal mutation carriers (i.e. $\mathrm{CDR}^{\circledR}$ plus NACC FTLD $=0.5$ ) where the therapeutic drug had an effect on the progression to being fully symptomatic (i.e. CDR $^{\circledR}$ plus NACC FTLD $=1$ ). We therefore calculated sample sizes for a $10 \%$, $20 \%$, and $40 \%$ effect size where a $100 \%$ treatment effect would be the difference in the mean between the $\mathrm{CDR}^{\circledR}$ plus NACC FTLD 0.5 and 1 groups. Choosing the effect size in this way assumes that the hypothetical treatment will prevent a given proportion of the decline in cognitive scores seen between these two groups. For example, a 20\% treatment effect assumes that the untreated group will experience the change seen between $\mathrm{CDR}^{\circledR}$ plus NACC FTLD 0.5 and 1 groups, but the treated group will only experience $80 \%$ of this change (i.e. $20 \%$ less). See Additional file 1 for more details on the sample size calculations and the parameters used (Additional file 1: Table S2) [41].

\section{Time-to-event analysis}

To provide recommendations on the timeline for the hypothesized trial, we present Kaplan-Meier curves showing the cumulative proportion of participants who progressed from a CDR ${ }^{\circledR}$ plus NACC FTLD 0.5 to $\geq 1$ within the GENFI cohort over time. In this analysis, the censoring date was the date of conversion or the date of the last follow-up. As this is an ongoing prospective cohort study, not all mutation carriers completed all study visits which resulted in missing data. There were 62 mutation carriers (19 C9orf72, 27 GRN, and 16 MAPT) that had a CDR ${ }^{\circledR}$ plus NACC FTLD of 0.5 and one or multiple follow-up visits and were included in the timeto-event analysis (Additional file 1: Table S4 and Fig. 1). A log rank test was performed to compare the rate of progression between the genetic groups.

\section{Results \\ Demographics}

Participant characteristics for all mutation carriers are summarized in Table 1. Overall, the number of males to females differed between the groups $(p=$ 0.020). C9orf72, GRN, and MAPT mutation carriers were older and had lower MMSE and higher $\mathrm{CDR}^{\circledR}$ plus NACC FTLD sum of boxes scores than controls (all $p<0.010$ ). In addition, C9orf72 mutation carriers had higher CDR ${ }^{\circledR}$ plus NACC FTLD sum of boxes scores than GRN mutation carriers $(p=0.007)$. There were no differences between the groups in years of education $(p=0.290)$. The characteristics of participants 


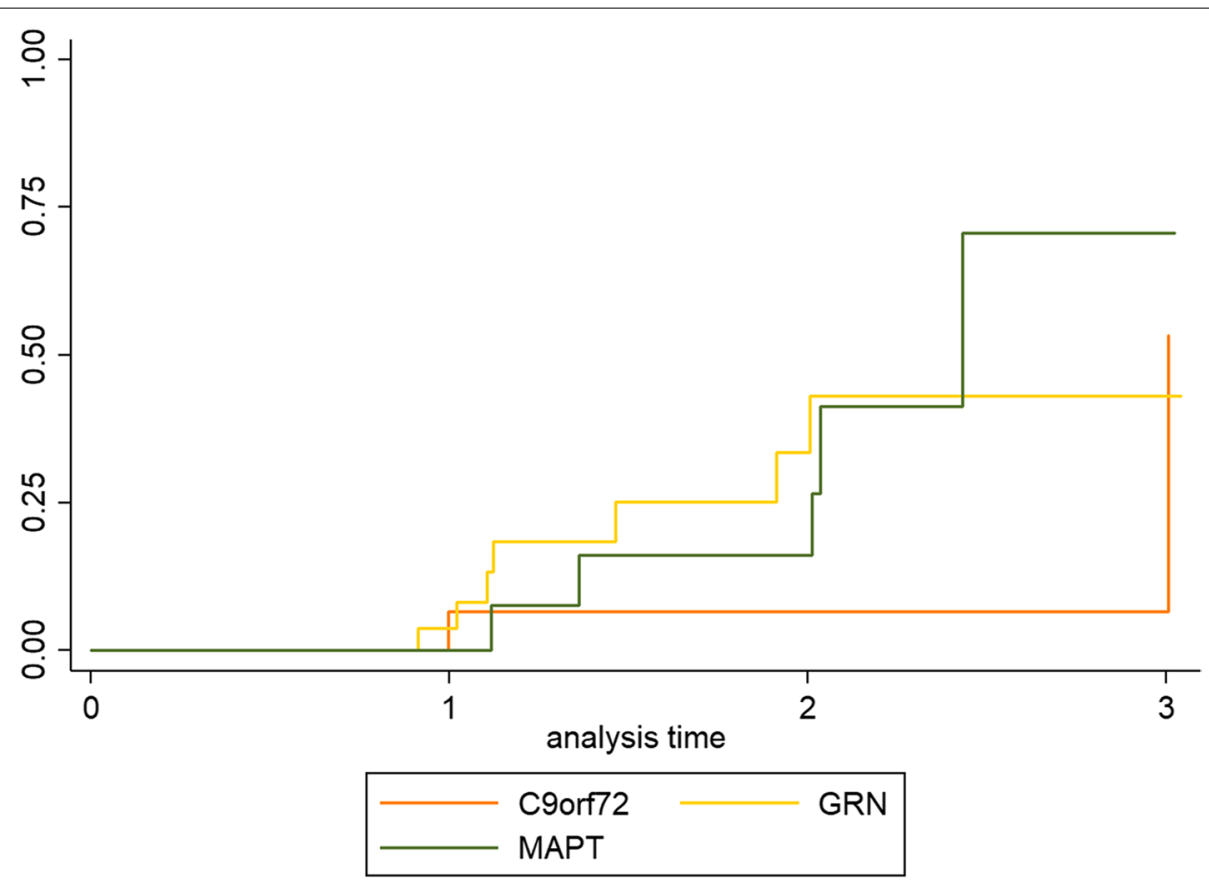

Fig. 1 Kaplan-Meier estimates of mutation carriers that converted from CDR ${ }^{\circledR}$ plus NACC FTLD 0.5 to $\geq 1$. The number of mutation carriers included, and the number that progressed or were lost to follow-up are reported in Additional file 1: Table 54. C9orf72, chromosome 9 open reading frame 72; GRN, progranulin; MAPT, microtubule-associated protein tau; CDR plus NACC FTLD, Clinical Dementia Rating scale plus National Alzheimer's Coordinating Center Frontotemporal Lobar Degeneration

when individually stratified by $\mathrm{CDR}^{\circledR}$ plus NACC FTLD global score (i.e. in $0.5,1,2$, and 3 groups) can be found in Additional file 1: Table S3.

\section{Logistic regression analyses}

The results from the logistic regression model can be seen in Table 2. A combination of category fluency, D-KEFS CWIT - colour, word and ink naming, TMT - part B, the Benson figure copy, FCSRT free recall, and the Facial Emotion Recognition Test was most sensitive to discriminate $C 9$ orf 72 repeat expansion carriers from controls. For GRN mutation carriers, a combination of the Camel and Cactus Test, TMT - part B, D-KEFS CWIT - ink naming, Benson figure recall, FCSRT total and delayed free recall, and the Facial Emotion Recognition Test was most sensitive. In MAPT mutation carriers, a combination of the Camel and Cactus Test, BNT, D-KEFS CWIT - colour naming, Benson figure recall, FCSRT free, total and delayed free recall, and the Facial Emotion Recognition Test was most sensitive to differentiate from controls. For each mutation carrier group, the average and weighted composite scores were calculated, including the tests with a negative coefficient in Table 2. A summary of the included tests that were included in each GENFI-Cog per gene group can be seen in Fig. 2.

\section{Sample size calculation}

Sample size estimates can be observed in Table 3. In C9orf72 repeat expansion carriers, both the average and weighted composite scores resulted in lower sample sizes than most individual cognitive tests. The only test that resulted in a lower sample size than the composite score was the D-KEFS CWIT - ink naming, with the digit symbol test also resulting in a lower sample size than the average but not the weighted composite score. In $G R N$ mutation carriers, again both composite scores resulted in lower sample sizes than for most individual cognitive tests except the TMT - part B. The TMT - part A also resulted in a lower sample size than the weighted composite, but not the average composite. In addition, the D-KEFS CWIT - ink naming resulted in a sample size of less than 100, albeit not lower than the composites. In MAPT mutation carriers, both composites resulted in estimated sample sizes smaller than 130 with an effect size of 0.1, but the TMT - part A, digit symbol test, and D-KEFS CWIT - colour and ink naming resulted in even lower sample sizes $(n<100)$. In C9orf72 and MAPT mutation carriers, the weighted composite score resulted in a lower estimated sample size than the 
Table 2 Regression coefficients and corresponding weights

\begin{tabular}{|c|c|c|c|c|c|c|}
\hline & \multicolumn{2}{|c|}{ C9orf72 } & \multicolumn{2}{|l|}{ GRN } & \multicolumn{2}{|l|}{ MAPT } \\
\hline & Coef. & Weight & Coef. & Weight & Coef. & Weight \\
\hline \multicolumn{7}{|l|}{ Language } \\
\hline Camel and Cactus Test & & & -0.004 & 0.003 & -0.04 & 0.04 \\
\hline Boston Naming Test & & & & & -0.39 & 0.40 \\
\hline Category fluency & -0.13 & 0.09 & & & & \\
\hline \multicolumn{7}{|l|}{ Attention and mental processing speed } \\
\hline \multicolumn{7}{|l|}{ Digit span forward } \\
\hline \multicolumn{7}{|l|}{ Trail Making Test - part A } \\
\hline \multicolumn{7}{|l|}{ Digit symbol } \\
\hline D-KEFS CWIT - colour naming & -0.06 & 0.04 & & & -0.09 & 0.09 \\
\hline D-KEFS CWIT - word naming & -0.04 & 0.03 & $0.09^{\mathrm{a}}$ & & & \\
\hline \multicolumn{7}{|l|}{ Executive function } \\
\hline \multicolumn{7}{|l|}{ Digit span backward } \\
\hline Trail Making Test - part B & -0.07 & 0.05 & -0.28 & 0.23 & & \\
\hline D-KEFS CWIT - ink naming & -0.29 & 0.20 & -0.24 & 0.20 & & \\
\hline Phonemic fluency & & & $0.24^{\mathrm{a}}$ & & & \\
\hline \multicolumn{7}{|l|}{ Visuoconstruction } \\
\hline Benson figure copy & -0.09 & 0.06 & & & & \\
\hline \multicolumn{7}{|l|}{ Memory } \\
\hline Benson figure recall & & & -0.06 & 0.05 & -0.01 & 0.01 \\
\hline FCSRT free recall & -0.50 & 0.35 & & & -0.06 & 0.06 \\
\hline FCSRT total recall & & & -0.05 & 0.04 & -0.30 & 0.31 \\
\hline FCSRT delayed free recall & & & -0.16 & 0.13 & -0.01 & 0.01 \\
\hline \multicolumn{7}{|l|}{ FCSRT delayed total recall } \\
\hline \multicolumn{7}{|l|}{ Social cognition } \\
\hline Facial Emotion Recognition Test & -0.26 & 0.18 & -0.42 & 0.35 & -0.08 & 0.08 \\
\hline
\end{tabular}

Data are presented as coefficients and weights. Coefficient gives the change in log odds of being a mutation carrier for each Z-score increase in the score on the cognitive test. Weight gives the weighting used when calculating the weighted cognitive composite score

Abbreviations: C9orf72 chromosome 9 open reading frame 72, GRN progranulin, MAPT microtubule-associated protein tau, D-KEFS CWIT Delis-Kaplan Executive Function System Colour-Word Interference Test, FCSRT Free and Cued Selective Reminding Test

a Positive coefficients indicate better performance in mutation carriers compared to controls and were not included in the composite score

\begin{tabular}{|c|c|c|}
\hline C9orf72 & GRN & MAPT \\
\hline Category fluency & Camel and Cactus Test & Camel and Cactus Test \\
\hline D-KEFS Color Word Interference Test - color and & \multirow{2}{*}{$\begin{array}{c}\text { D-KEFS Color Word Interference Test - ink naming } \\
\text { Trail Making Test - part B }\end{array}$} & Boston Naming Test \\
\hline word naming & & D-KEFS Color Word Interference Test - color naming \\
\hline $\begin{array}{c}\text { D-KEFS Color Word Interference Test - ink naming } \\
\text { Trail Making Test - part B }\end{array}$ & \multirow{3}{*}{$\begin{array}{c}\text { Benson Figure recall } \\
\text { FCSRT immediate total recall and delayed free recall } \\
\text { Facial Emotion Recognition test }\end{array}$} & \multirow{2}{*}{$\begin{array}{c}\text { Benson Figure recall } \\
\text { FCSRT immediate free and total recall }\end{array}$} \\
\hline & & \\
\hline Benson Figure copy & & \\
\hline FCSRT immediate free recall & Facial Emotion Recognition test & Facial Emotion Recognition test \\
\hline Facial Emotion Recognition test & & \\
\hline
\end{tabular}


Table 3 Sample size per arm for a hypothetical clinical trial using different cognitive outcome measures

\begin{tabular}{|c|c|c|c|c|c|c|c|c|c|}
\hline \multirow[t]{2}{*}{ Outcome measures } & \multicolumn{3}{|l|}{ C9orf72 } & \multicolumn{3}{|l|}{ GRN } & \multicolumn{3}{|l|}{ MAPT } \\
\hline & ES $10 \%$ & ES $20 \%$ & ES $40 \%$ & ES 10\% & ES $20 \%$ & ES $40 \%$ & ES $10 \%$ & ES $20 \%$ & ES $40 \%$ \\
\hline \multicolumn{10}{|l|}{ Cognitive composite scores } \\
\hline Average composite & 306 & 76 & 19 & 27 & 7 & 2 & 124 & 31 & 8 \\
\hline Weighted composite & 214 & 53 & 13 & 53 & 13 & 3 & 90 & 23 & 6 \\
\hline \multicolumn{10}{|l|}{ Language } \\
\hline Camel and Cactus Test & 4946 & 1237 & 309 & 292 & 73 & 18 & 357 & 89 & 22 \\
\hline Boston Naming Test & 1109 & 277 & 69 & 213 & 53 & 13 & 223 & 56 & 14 \\
\hline Category fluency & 1584 & 396 & 99 & 781 & 195 & 49 & 400 & 100 & 25 \\
\hline \multicolumn{10}{|c|}{ Attention and mental processing speed } \\
\hline Digit span forward & 13,0210 & 32,553 & 8138 & 2677 & 669 & 167 & 17,773 & 4443 & 1111 \\
\hline Trail Making Test - part A & 2272 & 568 & 142 & 45 & 11 & 3 & 69 & 17 & 4 \\
\hline Digit symbol & 254 & 64 & 16 & 925 & 231 & 58 & 80 & 20 & 5 \\
\hline D-KEFS CWIT - colour naming & 866 & 216 & 54 & 502 & 126 & 31 & 66 & 17 & 4 \\
\hline D-KEFS CWIT - word naming & 19,224 & 4806 & 1202 & 3310 & 828 & 207 & 150 & 37 & 9 \\
\hline \multicolumn{10}{|l|}{ Executive functioning } \\
\hline Digit span backward & 1724 & 431 & 108 & 840 & 210 & 52 & 26,218 & 6555 & 1639 \\
\hline Trail Making Test - part B & 1275 & 319 & 80 & 25 & 6 & 2 & 81 & 20 & 5 \\
\hline D-KEFS CWIT - ink naming & 61 & 15 & 4 & 70 & 17 & 4 & 26 & 7 & 2 \\
\hline Phonemic fluency & 558 & 139 & 35 & 2229 & 557 & 139 & 161 & 40 & 10 \\
\hline \multicolumn{10}{|l|}{ Visuoconstruction } \\
\hline Benson figure copy & 5911 & 1478 & 369 & 2119 & 530 & 132 & $6,282,036$ & $1,570,509$ & 392,627 \\
\hline \multicolumn{10}{|l|}{ Memory } \\
\hline Benson figure recall & 1044 & 261 & 65 & 657 & 164 & 41 & 7611 & 1903 & 476 \\
\hline FCSRT free recall & 1302 & 326 & 81 & 294 & 74 & 18 & 521 & 130 & 33 \\
\hline FCSRT total recall & 1020 & 255 & 64 & 477 & 119 & 30 & 524 & 131 & 33 \\
\hline FCSRT delayed free recall & 606 & 152 & 38 & 767 & 192 & 48 & 261 & 65 & 16 \\
\hline FCSRT delayed total recall & 358 & 89 & 22 & 193 & 48 & 12 & 681 & 170 & 43 \\
\hline \multicolumn{10}{|l|}{ Social cognition } \\
\hline Facial Emotion Recognition Test & 7570 & 1892 & 473 & 7805 & 1951 & 488 & 147 & 37 & 9 \\
\hline
\end{tabular}

The sample size per arm was estimated as $n=\left(1-\rho^{\wedge} 2\right)\left(2 \sigma^{\wedge} 2\right) / \delta \wedge 2 f(a, \beta)$, where $\rho$ is the correlation between baseline and follow-up measures of the outcome, $\sigma$ is the standard deviation of the outcome in the CDR ${ }^{\circledR}$ plus NACC-FTLD 0.5 group, $\delta$ is the treatment effect (effect size multiplied by the difference in mean between $\mathrm{CDR}^{\circledR}$ plus NACC-FTLD 0.5 and 1 group), $a$ is the significance level (0.05), and $1-\beta$ is the power to detect a treatment effect (80\%)

Abbreviations: C9orf72 chromosome 9 open reading frame $72, G R N$ progranulin, MAPT microtubule-associated protein tau, ES effect size as a proportion of the difference between the outcome in the CDR ${ }^{\circledR}$ plus NACC-FTLD 0.5 group and the outcome in the CDR ${ }^{\circledR}$ plus NACC-FTLD 1 group, D-KEFS CWIT Delis-Kaplan Executive Function System Colour-Word Interference Test, FCSRT Free and Cued Selective Reminding Test

average composite, whereas in GRN mutation carriers the average composite resulted in a lower sample size. For GRN (all $n<60$ ) and MAPT (all $n<125$ ) mutation carriers, lower sample sizes would be necessary to detect a treatment effect than for $C 9$ orf 72 repeat expansion carriers (all $n \leq 306)$.

\section{Time-to-event analysis}

Kaplan-Meier curves can be seen in Fig. 1, and details on the sample included in the time-to-event analysis are reported in Additional file 1: Table S4. For C9orf72 repeat expansion carriers, the probability of converting to a $\mathrm{CDR}^{\circledR}$ plus NACC FTLD of $\geq 1$ increases from $6 \%$ after 2 years $(\mathrm{SE}=0.06,95 \% \mathrm{CI} 0.01-0.39)$ to $53 \%$ after 3 years ( $\mathrm{SE}=0.33$, 95\% CI 0.12-0.99). In GRN mutation carriers, the probability of converting to a $\mathrm{CDR}^{\circledR}$ plus NACC FTLD of $\geq 1$ increased from $4 \%$ after 1 year $(\mathrm{SE}=0.04$, $95 \%$ CI $0.01-0.24$ ) to $43 \%$ after 3 years $(\mathrm{SE}=0.14,95 \%$ CI 0.22-0.72). In $M A P T$ mutation carriers, the probability of converting to a global score of $\geq 1$ increased from $10 \%$ after 1 year $(\mathrm{SE}=0.10,95 \% \mathrm{CI} 0.01-0.49)$ to $42 \%$ during the second year ( $\mathrm{SE}=0.20,95 \% \mathrm{CI} 0.14-0.85$ ). The Kaplan-Meier curve for MAPT mutation increased to $100 \%$ after 3 years in Fig. 1 because only one mutation carrier had follow-up up to this point and this individual progressed to a $\mathrm{CDR}^{\circledR}$ plus NACC FTLD of $\geq 1$. There 
was no significant difference between the progression rates of different genetic groups $\left(X^{2}(2)=1.18, p=0.55\right)$. In the total group of mutation carriers, the probability of converting to a $\mathrm{CDR}^{\circledR}$ plus NACC FTLD of $\geq 1$ was $21 \%$ after 2 years $(\mathrm{SE}=0.03,95 \% \mathrm{CI} 0.11-0.40)$ and $52 \%$ after 3 years $(\mathrm{SE}=0.16,95 \% \mathrm{CI} 0.26-0.83)$. This means that for a 3-year trial where drug treatment is assumed to have s $20 \%$ effect (i.e. only $80 \%$ of the treated group will experience the change seen between $\mathrm{CDR}^{\circledR}$ plus NACC FTLD 0.5 and 1 groups), the sample size corresponding to a $10 \%$ effect in Table 3 needs to be included in order to demonstrate a treatment effect, because only 50\% of mutation carriers would be expected to progress from $\mathrm{CDR}^{\circledR}$ plus NACC FTLD 0.5 to 1 without treatment (i.e. effect size needs to be divided by 2 ).

\section{Discussion}

We have empirically developed gene-specific cognitive composite scores in MAPT, GRN, and C9orf72 mutation carriers (GENFI-Cog) and demonstrated that they provide feasible sample sizes for clinical trials to evaluate the effect of treatment on clinical progression from the prodromal to the fully symptomatic stage. Time-to-event analyses revealed that roughly $50 \%$ of the patients with a $\mathrm{CDR}^{\circledR}$ plus NACC FTLD of 0.5 progress to 1 or higher after a period of 3 years. The results from this study show that GENFI-Cog has potential as a cognitive endpoint in upcoming clinical trials and provide important guidelines on sample size recruitment and clinical trial duration.

The GENFI-Cog composites can be regarded as attractive clinical outcome measures because they produce substantially lower sample size estimates than most individual neuropsychological tests. Depending on the effect size (40\% to $10 \%)$, sample size estimates ranged between 13 and 214 for C9orf72, 3 and 53 for GRN, and 6 and 90 for MAPT per study arm for the weighted GENFI-Cog. A practical problem in trial design for FTD spectrum disorders is recruiting enough patients to test candidate therapeutics as FTD is much less common than AD, with an estimated prevalence of $15 / 100,000$ and approximately $10-20 \%$ of cases being caused by mutations in C9orf72, $G R N$, and MAPT genes [4, 7, 42]. It is therefore unlikely that a trial would be able to include many hundreds of patients per study arm, which our results showed would be necessary for most individual neuropsychological tests. There were some individual neuropsychological tests that required reasonable sample sizes similar to that of GENFI-Cog, e.g. TMT and D-KEFS CWIT. These tests are typically included in clinical trials such as the current AL001 study of GRN-related FTD [7]. Yet, due to the heterogeneity in cognitive symptoms between patients even with the same genetic mutation, individually examining each cognitive test might not provide a sensitive and clinically meaningful primary outcome measure. Using GENFI-Cog will allow a single cognitive outcome to be used when analysing treatment effect, although validation in other large cohorts is warranted.

The $\mathrm{CDR}^{\circledR}$ plus NACC FTLD is currently often used as an inclusion criterion for clinical trials as well as for tracking disease progression. The results showed that roughly $50 \%$ of the patients with a $\mathrm{CDR}^{\circledR}$ plus NACC FTLD 0.5 progress to 1 or higher after a period of 3 years. This indicates that for trials with a duration of 3 years, around $50 \%$ of patients with $\mathrm{CDR}^{\circledR}$ plus NACC FTLD of 0.5 on entry to the trial would be expected to progress to $\mathrm{CDR}^{\circledR}$ plus NACC FTLD of 1 in the absence of effective disease-modifying treatment. This means that if a treatment is expected to have a $20 \%$ effect, the sample size corresponding to a $10 \%$ effect needs to be included per study arm to be able to demonstrate a treatment effect, because only half of the mutation carriers would be expected to progress from CDR ${ }^{\circledR}$ plus NACC FTLD 0.5 to 1 without treatment. This is important to consider when planning trial duration and recruitment with the currently available clinical measures.

The optimal gene-specific cognitive composite score incorporated tests from different cognitive domains. For GRN mutation carriers, tests for executive function and social cognition contributed the most to the composite score, with the addition of tests for memory and language. In MAPT mutation carriers, there was a strong focus on semantic and episodic memory tests in the composite score with the addition of tests for attention and mental processing speed. A combination of tests from all cognitive domains was most sensitive in C9orf72 mutation carriers, with the strongest contribution from tests within the domains of executive function, social cognition, and memory. These results complement recent studies showing cognitive decline in the early stages of FTD with widespread cognitive impairment covering multiple domains in C9orf72 [22, 43], dysexecutive functioning as the key feature in $G R N[13,22]$ and a specific impairment in episodic and semantic memory in $M A P T$-associated FTD [13, 20, 22]. Impairment of social cognition appears to be a key feature in all three genetic groups [38], which was probably due to the high number of bvFTD cases in the sample. Neuroimaging studies have indeed shown that the neurodegenerative process in C9orf 72 mutation carriers typically is reflected by widespread degeneration in frontal, temporal, and cerebellar and subcortical structures [43], whereas focal atrophy of the anteromedial temporal lobe, an area important for memory and semantic functioning, is often seen in $M A P T$-associated FTD [44]. In GRN mutation carriers, the typical pattern of degeneration includes the inferior frontal regions as well as the cingulate cortex, areas known to be critical 
in executive function [44]. Thus, although the GENFICog was empirically derived, the selected tests are clinically meaningful and in line with a theoretically driven approach where the composite would be constructed a priori from cognitive tests that are known to decline in the early stages of each genetic group.

This is to our knowledge the first study that has created cognitive composites for genetic forms of FTD by selecting the most sensitive combinations of cognitive variables based on systematic comparisons with controls. A major strength of this study is the use of a large cohort of genetic FTD mutation carriers allowing gene-specific analyses, but also the use of a matched control group of mutation-negative family members. Another strength is the use of LASSO with cross-validation to avoid overfitting bias to ensure that results have generalizability [41].

\section{Limitations}

There are some limitations to the present study, however. The results from the logistic regression analysis revealed two neuropsychological tests in GRN mutation carriers with a positive coefficient, indicating better performance compared to controls, and were excluded from the composite scores. Development of GENFI-Cog was constrained by the neuropsychological test battery that is used in the GENFI cohort [14], which made validation in an independent sample not possible and limited the generalizability of the findings. Validation in other cohorts (such as ALLFTD [45] or DINAD) is therefore recommended. Although the LASSO model with 10-fold cross-validation included an internal cross-validation step to select the penalization term for the selection of the cognitive tests, the findings were not externally validated in an independent sample thereby limiting the generalizability of GENFI-Cog. Future collaborations within the FTD Prevention Initiative (FPI) could be a starting point to cross-validate our findings. The sample size estimates serve as a guide on the sensitivity and power of GENFI-Cog compared to individual cognitive tests and should be interpreted with caution as they were calculated from the cross-sectional difference between a small number of patients with $\mathrm{CDR}^{\circledR}$ plus NACC FTLD 0.5 and 1 , assuming that the difference between these groups is representative of the change over time that would be seen in longitudinal scores in a clinical trial as patients progress from a score of 0.5 to 1 , i.e. prodromal to fully symptomatic. Future research using longitudinal data and larger sample sizes is necessary to examine the validity of this assumption and to examine if the cognitive composites presented in the current study are similar to those derived using longitudinal change in scores. Importantly, it is essential for future clinical trials of FTD to also include other biomarkers such as neuroimaging, neurofilament light chain, or other fluid protein levels as endpoints. As such, it would be interesting to include such biomarkers in addition to GENFI-Cog within a future longitudinal multimodal analysis. Lastly, as GENFI is a prospective cohort study with ongoing recruitment, not all participants completed the same number of visits contributing to low sample sizes at later visits in the time-to-event analysis. The time-to-event analysis was performed to provide insight on the possible duration required for a clinical trial, but validation with larger sample sizes where all participants have completed the same number of visits is warranted.

\section{Conclusions}

In summary, we examined the cognitive data from the GENFI cohort and conducted a search for the combination of cognitive assessments most sensitive to differentiate $M A P T, G R N$, and $C 9$ orf72 mutation carriers from non-carriers. As a result, we created three gene-specific cognitive composite scores, GENFI-Cog, that were sensitive to track progression on the clinical progression of the $\mathrm{CDR}^{\circledR}$ plus NACC FTLD 0.5 to 1 stage as it resulted in smaller sample sizes than most individual neuropsychological tests. To conclude, GENFI-Cog has the potential to be a primary cognitive outcome measure in upcoming clinical trials for C9orf72, GRN, and MAPT mutation carriers.

\section{Abbreviations \\ AD: Alzheimer's disease; ADAS-Cog: Alzheimer's Disease Assessment Scale Cognitive Subscale; ALLFTD: ARTFL-LEFFTDS Longitudinal Frontotemporal Lobar Degeneration Study; BNT: Boston Naming Test; bvFTD: Behavioural variant frontotemporal dementia; C9orf72: Chromosome 9 open reading frame 72; CDR plus NACC-FTLD: Clinical Dementia Rating scale plus National Alzheimer's Coordinating Center - Frontotemporal Lobar Degeneration; CWIT: Colour Word Interference Test; DINAD: Dominantly inherited non-Alzheimer dementias; D-KEFS: Delis-Kaplan Execution Function System; FCSRT: Free and Cued Selective Reminding Test; FTD: Frontotemporal dementia; FTD-ALS: Fron- totemporal dementia with amyotrophic lateral sclerosis; GENFI: Genetic FTD Initiative; GRN: Progranulin; HD: Huntington's disease; LASSO: Least absolute shrinkage and selection operator; MAPT: Microtubule-associated protein tau; MMSE: Mini-Mental State Examination; PD: Parkinson's disease; PPA: Primary progressive aphasia; TMT:Trail Making Test; UPDRS: Unified Parkinson's Disease Rating Scale; UHDRS: Unified Huntington's Disease Rating Scale; WAIS-R: Wechsler Adult Intelligence Scale - Revised; WMS-R: Wechsler Memory Scale - Revised.}

\section{Supplementary Information}

The online version contains supplementary material available at https://doi. org/10.1186/s13195-022-00958-0.

Additional file 1: Table S1. Number of control data available in each language per cognitive test. Table S2. Parameters included in the sample size calculations. Table S3. Participants characteristics and neuropsychological test results per CDR ${ }^{\circledR}$ plus NACC FTLD global score. Table S4. Number of mutation carriers that progressed on the CDR ${ }^{\circledR}$ plus NACC FTLD. Figure S1. STROBE flowchart. 


\section{Acknowledgements}

We thank the research participants and their families for their contribution to the study. Several authors of this publication are members of the European Reference Network for Rare Neurological Diseases - Project ID No 739510. Group authorship for the Genetic FTD Initiative:

Arabella Bouzigues MSC ${ }^{1}$, Martin N. Rossor MD FRCP ${ }^{1}$, Nick C. Fox MD FRCP', Jason D. Warren PhD FRACP ${ }^{1}$, Martina Bocchetta PhD ${ }^{1}$, Imogen J. Swift MSc', Rachelle Shafei MRCP ${ }^{1}$, Carolin Heller BSc ${ }^{1}$, Emily Todd $\mathrm{MSC}^{1}$, David Cash PhD', lone Woollacott PhD ${ }^{1}$, Henrik Zetterberg ${ }^{1}$, Annabel Nelson BSc ${ }^{1}$, Rita Guerreiro PhD², Jose Bras PhD², David L. Thomas PhD ${ }^{3}$, Simon Mead PhD ${ }^{4}$, Lieke Meeter MD ${ }^{5}$, Jessica Panman $\mathrm{MSc}^{5}$, Rick van Minkelen $\mathrm{PhD}^{6}$, Myriam Barandiaran $\mathrm{PhD}^{7,8}$, Begoña Indakoetxea $\mathrm{MD}^{7,8}$, Alazne Gabilondo MD ${ }^{8}$, Mikel Tainta $\mathrm{MD}^{8}$, Ana Gorostidi $\mathrm{PhD}^{8}$, Miren Zulaica $\mathrm{BSC}^{8}$, Alina Díez $\mathrm{MSc}^{8}$, Jorge Villanua MD PhD ${ }^{9}$, Sergi Borrego-Ecija MD ${ }^{10}$, Jaume Olives $\mathrm{MSc}^{10}$, Albert Lladó $\mathrm{PhD}^{10}$, Mircea Balasa PhD ${ }^{10}$, Anna Antonell $\mathrm{PhD}^{10}$, Nuria Bargallo PhD ${ }^{11}$, Enrico Premi MD ${ }^{12}$, Stefano Gazzina MD ${ }^{13}$, Roberto Gasparotti MD ${ }^{14}$, Silvana Archetti MBiolSci ${ }^{15}$, Sandra Black MD ${ }^{16}$, Sara Mitchell MD ${ }^{16}$, Ekaterina Rogaeva PhD ${ }^{17}$, Morris Freedman MD ${ }^{18}$, Ron Keren MD ${ }^{19}$, David Tang-Wai MD ${ }^{20}$, Hakan Thonberg $\mathrm{MD}^{21}$, Linn Öijerstedt MD ${ }^{21,22}$, Christin Andersson PhD ${ }^{23}$, Vesna Jelic MD ${ }^{24}$ Andrea Arighi MD ${ }^{25,26}$, Chiara Fenoglio PhD ${ }^{25,26}$, Elio Scarpini MD ${ }^{25,26}$, Giorgio Fumagalli MD ${ }^{25,26}$, Thomas Cope MRCP ${ }^{27}$, Carolyn Timberlake BSC ${ }^{27}$, Timothy Rittman MRCP ${ }^{27}$, Christen Shoesmith MD ${ }^{28}$, Robart Bartha PhD ${ }^{29,30}$, Rosa Rademakers PhD ${ }^{31}$, Carlo Wilke MD ${ }^{32,33}$, Hans-Otto Karnarth MD $^{34}$, Benjamin Bender MD ${ }^{35}$, Rose Bruffaerts MD PhD ${ }^{36}$, Philip Vandamme MD PhD ${ }^{37}$, Mathieu Vandenbulcke MD PhD ${ }^{38,39}$, Catarina B. Ferreira $\mathrm{MSC}^{40}$, Gabriel Miltenberger $\mathrm{PhD}^{41}$, Carolina Maruta MPsych PhD ${ }^{42}$, Ana Verdelho MD PhD ${ }^{43}$, Sónia Afonso $\mathrm{BSC}^{44}$, Ricardo Taipa MD PhD ${ }^{45}$, Paola Caroppo MD PhD ${ }^{46}$, Giuseppe Di Fede MD PhD ${ }^{46}$, Giorgio Giaccone MD ${ }^{46}$, Sara Prioni PsyD ${ }^{46}$, Veronica Redaelli MD ${ }^{46}$, Giacomina Rossi MSc ${ }^{46}$, Diana Duro NPsych ${ }^{47}$, Maria Rosario Almeida PhD ${ }^{47}$, Miguel Castelo-Branco MD PhD ${ }^{47}$, Maria João Leitão BSc ${ }^{48}$, Miguel TabuasPereira $\mathrm{MD}^{49}$, Beatriz Santiago MD ${ }^{49}$, Serge Gauthier MD ${ }^{50}$, Pedro Rosa-Neto MD PhD ${ }^{51}$, Michele Veldsman PhD ${ }^{52}$, Paul Thompson PhD ${ }^{53}$, Tobias Langheinrich $\mathrm{MD}^{53}$, Catharina Prix MD ${ }^{54}$, Tobias Hoegen $\mathrm{MD}^{54}$, Elisabeth Wlasich Mag. rer. nat. ${ }^{54}$, Sandra Loosli MD ${ }^{54}$, Sonja Schonecker MD ${ }^{54}$, Sarah Anderl-Straub Dr.hum.biol Dipl.Psych ${ }^{55}$, Jolina Lombardi ${ }^{55}$, Nuria Bargalló MD PhD ${ }^{56}$, Alberto Benussi MD ${ }^{57}$, Valentina Cantoni ${ }^{57}$, Maxime Bertoux PhD ${ }^{58,59}$, Anne Bertrand MD PhD ${ }^{60}$, Alexis Brice MD PhD ${ }^{60}$, Agnès Camuzat ${ }^{60}$, Olivier Colliot PhD ${ }^{60}$, Sabrina Sayah ${ }^{60}$, Aurélie Funkiewiez ${ }^{60,61}$, Daisy Rinaldi ${ }^{60,61}$, Gemma Lombardi ${ }^{61}$, Benedetta Nacmias ${ }^{61}$, Dario Saracino $60,61,62$, Valentina Bessi ${ }^{63}$, Camilla Ferrari ${ }^{63}$, Marta Cañada ${ }^{64}$, Vincent Deramecourt ${ }^{65}$, Gregory Kuchcinski ${ }^{65}$, Thibaud Lebouvier $^{65}$, Sebastien Ourselin ${ }^{66}$, Cristina Polito ${ }^{67}$, and Adeline Rollin ${ }^{68}$ 1 Dementia Research Centre, Department of Neurodegenerative Disease, UCL Institute of Neurology, Queen Square, London, UK; ${ }^{2}$ Center for Neurodegenerative Science, Van Andel Institute, Grand Rapids, Michigan, MI 49503, USA; ${ }^{3}$ Division of Neuroscience and Experimental Psychology, Wolfson Molecular Imaging Centre, University of Manchester, Manchester, UK; ${ }^{4} \mathrm{MRC}$ Prion Unit, Department of Neurodegenerative Disease, $U C L$ Institute of Neurology, Queen Square, London, UK; ${ }^{5}$ Department of Neurology, Erasmus Medical Center, Rotterdam, The Netherlands; ${ }^{6}$ Department of Clinical Genetics, Erasmus Medical Center, Rotterdam, The Netherlands; ${ }^{7}$ Cognitive Disorders Unit, Department of Neurology, Donostia University Hospital, San Sebastian, Gipuzkoa, Spain; ${ }^{8}$ Neuroscience Area, Biodonostia Health Research Insitute, San Sebastian, Gipuzkoa, Spain; ${ }^{9}$ OSATEK, University of Donostia, San Sebastian, Gipuzkoa, Spain; ${ }^{10}$ Alzheimer's Disease and Other Cognitive Disorders Unit, Neurology Service, Hospital Clínic, Barcelona, Spain; ${ }^{11}$ Imaging Diagnostic Center, Hospital Clínic, Barcelona, Spain; ${ }^{12}$ Stroke Unit, ASST Brescia Hospital, Brescia, Italy; ${ }^{13}$ Neurology, ASST Brescia Hospital, Brescia, Italy; ${ }^{14}$ Neuroradiology Unit, University of Brescia, Brescia, Italy; ${ }^{15}$ Biotechnology Laboratory, Department of Diagnostics, ASST Brescia Hospital, Brescia, Italy; ${ }^{16}$ Sunnybrook Health Sciences Centre, Sunnybrook Research Institute, University of Toronto, Toronto, Canada; ${ }^{17}$ Tanz Centre for Research in Neurodegenerative Diseases, University of Toronto, Toronto, Canada; ${ }^{18}$ Baycrest Health Sciences, Rotman Research Institute, University of Toronto, Toronto, Canada; ${ }^{19}$ The University Health Network, Toronto Rehabilitation Institute, Toronto, Canada; ${ }^{20}$ The University Health Network, Krembil Research Institute, Toronto, Canada; ${ }^{21}$ Center for Alzheimer Research, Division of Neurogeriatrics, Department of Neurobiology, Care Sciences and Society, Bioclinicum, Karolinska Institutet, Solna, Sweden; ${ }^{22}$ Unit for Hereditary Dementias, Theme Aging, Karolinska University Hospital, Solna, Sweden; ${ }^{23}$ Department of Clinical Neuroscience, Karolinska Institutet, Stockholm, Sweden; ${ }^{24}$ Division of Clinical Geriatrics, Karolinska Institutet, Stockholm, Sweden; ${ }^{25}$ Fondazione IRCCS Ca' Granda
Ospedale Maggiore Policlinico, Neurodegenerative Diseases Unit, Milan, Italy; ${ }^{26}$ University of Milan, Centro Dino Ferrari, Milan, Italy; ${ }^{27}$ Department of Clinical Neuroscience, University of Cambridge, Cambridge, UK; ${ }^{28}$ Department of Clinical Neurological Sciences, University of Western Ontario, London, Ontario, Canada; ${ }^{29}$ Department of Medical Biophysics, The University of Western Ontario, London, Ontario, Canada; ${ }^{30}$ Centre for Functional and Metabolic Mapping, Robarts Research Institute, The University of Western Ontario, London, Ontario, Canada; ${ }^{31}$ Department of Neurosciences, Mayo Clinic, Jacksonville, FL, USA; ${ }^{32}$ Department of Neurodegenerative Diseases, Hertie-Institute for Clinical Brain Research and Center of Neurology, University of Tübingen, Tübingen, Germany; ${ }^{33}$ Center for Neurodegenerative Diseases (DZNE), Tübingen, Germany; ${ }^{34}$ Division of Neuropsychology, Hertie-Institute for Clinical Brain Research and Center of Neurology, University of Tübingen, Tübingen, Germany; ${ }^{35}$ Department of Diagnostic and Interventional Neuroradiology, University of Tübingen, Tübingen, Germany; ${ }^{36}$ Laboratory for Cognitive Neurology, Department of Neurosciences, KU Leuven, Leuven, Belgium; ${ }^{37}$ Neurology Service, University Hospitals Leuven, Belgium; Laboratory for Neurobiology, VIB-KU Leuven Centre for Brain Research, Leuven, Belgium; ${ }^{38}$ Geriatric Psychiatry Service, University Hospitals Leuven, Leuven, Belgium; ${ }^{39}$ Neuropsychiatry, Department of Neurosciences, KU Leuven, Leuven, Belgium; ${ }^{40}$ Laboratory of Neurosciences, Institute of Molecular Medicine, Faculty of Medicine, University of Lisbon, Lisbon, Portugal; ${ }^{41}$ Faculty of Medicine, University of Lisbon, Lisbon, Portugal; ${ }^{42}$ Laboratory of Language Research, Centro de Estudos Egas Moniz, Faculty of Medicine, University of Lisbon, Lisbon, Portugal; ${ }^{43}$ Department of Neurosciences and Mental Health, Centro Hospitalar Lisboa Norte - Hospital de Santa Maria \& Faculty of Medicine, University of Lisbon, Lisbon, Portugal; ${ }^{44}$ Instituto Ciencias Nucleares Aplicadas a Saude, Universidade de Coimbra, Coimbra, Portugal; ${ }^{45}$ Neuropathology Unit and Department of Neurology, Centro Hospitalar do Porto - Hospital de Santo António, Oporto, Portugal; ${ }^{46}$ Fondazione IRCCS Istituto Neurologico Carlo Besta, Milan, Italy; ${ }^{47}$ Faculty of Medicine, University of Coimbra, Coimbra, Portugal; ${ }^{48}$ Centre of Neurosciences and Cell Biology, Universidade de Coimbra, Coimbra, Portugal; ${ }^{49}$ Neurology Department, Centro Hospitalar e Universitario de Coimbra, Coimbra, Portugal; ${ }^{50}$ Alzheimer Disease Research Unit, McGill Centre for Studies in Aging, Department of Neurology \& Neurosurgery, McGill University, Montreal, Québec, Canada; ${ }^{51}$ Translational Neuroimaging Laboratory, McGill Centre for Studies in Aging, McGill University, Montreal, Québec, Canada; ${ }^{52}$ Nuffield Department of Clinical Neurosciences, Medical Sciences Division, University of Oxford, Oxford, UK; ${ }^{53}$ Division of Neuroscience and Experimental Psychology, Wolfson Molecular Imaging Centre, University of Manchester, Manchester, UK; ${ }^{54}$ Neurologische Klinik, Ludwig-Maximilians-Universität München, Munich, Germany; ${ }^{55}$ Department of Neurology, University of Ulm, Ulm, Germany; ${ }^{56}$ Imaging Diagnostic Center, Hospital Clínic, Barcelona, Spain; ${ }^{57}$ Centre for Neurodegenerative Disorders, Department of Clinical and Experimental Sciences, University of Brescia, Brescia, Italy; ${ }^{58}$ Inserm 1172 , Lille, France; ${ }^{59} \mathrm{CHU}$, CNR-MAJ, Labex Distalz, LiCEND, Lille, France, ${ }^{60}$ Sorbonne Université, Paris Brain Institute Institut du Cerveau - ICM, Inserm U1127, CNRS UMR 7225, AP-HP - Hôpital Pitié-Salpêtrière, Paris, France; ${ }^{61}$ Centre de référence des démences rares ou précoces, IM2A, Département de Neurologie, AP-HP - Hôpital Pitié-Salpêtrière, Paris, France; ${ }^{62}$ Inria, Aramis project-team, F-75013, Paris, France ${ }^{63}$ Department of Neuroscience, Psychology, Drug Research and Child Health, University of Florence, Florence, Italy; ${ }^{64} \mathrm{CITA}$ Alzheimer, San Sebastian, Gipuzkoa, Spain; ${ }^{65}$ University of Lille, Lille, France; ${ }^{66}$ School of Biomedical Engineering \& Imaging Sciences, King's College London, London, UK; ${ }^{67}$ Department of Biomedical, Experimental and Clinical Sciences "Mario Serio", Nuclear Medicine Unit, University of Florence, Florence, Italy; ${ }^{68} \mathrm{CHU}, \mathrm{CNR}-\mathrm{MAJ}$, Labex Distalz, LiCEND, Lille, France

\section{Authors' contributions}

JMP, KMM, JN, and JDR contributed to the conception and design of the work and the analysis of the data. JMP drafted the original work. All authors contributed to the acquisition and interpretation of the data and revised the work. All authors read and approved the final manuscript.

\section{Funding}

The Dementia Research Centre is supported by Alzheimer's Research UK, Alzheimer's Society, Brain Research UK, and The Wolfson Foundation. This work was supported by the NIHR UCL/H Biomedical Research Centre, the Leonard Wolfson Experimental Neurology Centre (LWENC) Clinical Research Facility, and the UK Dementia Research Institute, which receives its funding from UK DRI Ltd., funded by the UK Medical Research Council, Alzheimer's Society 
and Alzheimer's Research UK. JDR is supported by an MRC Clinician Scientist Fellowship (MR/M008525/1) and has received funding from the NIHR Rare Dis ease Translational Research Collaboration (BRC149/NS/MH). This work was also supported by the MRC UK GENFI grant (MR/M023664/1), the Bluefield Project, the JPND GENFI-PROX grant (2019-02248), the Dioraphte Foundation [grant numbers 09-02-00], the Association for Frontotemporal Dementias Research Grant 2009, The Netherlands Organization for Scientific Research (NWO) (grant HCMI 056-13-018), ZonMw Memorabel (Deltaplan Dementie, (project numbers 733050103 and 733050 813), and JPND PreFrontAls Consortium (project number 733051042). JM Poos is supported by a fellowship award from Alzheimer Nederland (WE.15-2019.02). This work was conducted using the MRC Dementias Platform UK (MR/L023784/1 and MR/009076/1).

\section{Availability of data and materials}

The datasets used and/or analysed during the current study are available from the corresponding author on reasonable request

\section{Declarations}

\section{Ethics approval and consent to participate}

All GENFI sites had local ethical approval for the study, and all participants gave written informed consent.

\section{Consent for publication}

$$
\text { Not applicable }
$$

\section{Competing interests}

The authors declare that they have no competing interests.

\section{Author details}

${ }^{1}$ Department of Neurology, Erasmus MC University Medical Center, Rotterdam, The Netherlands. ${ }^{2}$ Dementia Research Centre, Department of Neurodegenerative Disease, National Hospital for Neurology and Neurosurgery, UCL Institute of Neurology, 8-11 Queen Square, Box 16, London WC1N 3BG, UK. ${ }^{3}$ Department of Medical Statistics, London School of Hygiene and Tropical Medicine, London, UK. ${ }^{4}$ Department of Neurology, Alzheimer Center, Amsterdam University Medical Center, Amsterdam Neuroscience, Amsterdam, The Netherlands. ${ }^{5}$ Cognitive Disorders Unit, Department of Neurology, Donostia University Hospital, San Sebastian, Gipuzkoa, Spain. ${ }^{6}$ Alzheimer's disease and Other Cognitive Disorders Unit, Neurology Service, Hospital Clínic, Institut d'Investigacións Biomèdiques August Pi I Sunyer, University of Barcelona, Barcelona, Spain. ${ }^{7}$ Centre for Neurodegenerative Disorders, Neurology Unit, Department of Clinical and Experimental Sciences, University of Brescia, Brescia, Italy. ${ }^{8}$ Clinique Interdisciplinaire de Mémoire, Département des Sciences Neurologiques, Université Laval, Québec, Canada. ${ }^{9}$ Sunnybrook Health Sciences Centre, Sunnybrook Research Institute, University of Toronto, Toronto, Canada. ${ }^{10}$ Tanz Centre for Research in Neurodegenerative Diseases, University of Toronto, Toronto, Canada. ${ }^{11}$ Department of Geriatric Medicine, Karolinska University Hospital-Huddinge, Stockholm, Sweden. ${ }^{12}$ University of Milan, Centro Dino Ferrari, Milan, Italy. ${ }^{13}$ Neurodegenerative Diseases Unit, Fondazione IRCCS Ca' Granda, Ospedale Policlinico, Milan, Italy. ${ }^{14}$ Department of Clinical Neurosciences, University of Cambridge, Cambridge, UK. ${ }^{15}$ Department of Clinical Neurological Sciences, University of Western Ontario, London, Ontario, Canada. ${ }^{16}$ Department of Neurodegenerative Diseases, Hertie-Institute for Clinical Brain Research and Center of Neurology, University of Tübingen, Tübingen, Germany. ${ }^{17}$ German Center for Neurodegenerative Diseases (DZNE), Tübingen, Germany. ${ }^{18}$ Laboratory for Cognitive Neurology, Department of Neurosciences, KU Leuven, Leuven, Belgium. ${ }^{19}$ Faculty of Medicine, University of Lisbon, Lisbon, Portugal. ${ }^{20}$ Fondazione Istituto di Ricovero e Cura a Carattere Scientifico Istituto Neurologica Carlo Besta, Milan, Italy. ${ }^{21}$ Faculty of Medicine, University of Coimbra, Coimbra, Portugal. ${ }^{22}$ Department of Psychiatry, McGill University Health Centre, McGill University, Montreal, Québec, Canada. ${ }^{23}$ Department of Clinical Neurology, University of Oxford, Oxford, UK. ${ }^{24}$ Faculty of Medical and Human Sciences, Institute of Brain, Behaviour and Mental Health, University of Manchester, Manchester, UK. ${ }^{25}$ Department of Neurology, Ludwig-Maximilians-University, Munich, Germany. ${ }^{26}$ German Center for Neurodegenerative Diseases (DZNE), Munich, Germany. ${ }^{27}$ Munich Cluster for Systems Neurology (SyNergy), Munich, Germany. ${ }^{28}$ Department of Neurology, University of UIm, UIm, Germany. ${ }^{29}$ Paris Brain Institute - Institut du Cerveau - ICM, Inserm U1127, CNRS UMR 7225,
AP-HP - Hôpital Pitié-Salpêtrière, Sorbonne Université, Paris, France. ${ }^{30}$ Centre de référence des démences rares ou précoces, IM2A, Département de Neurologie, AP-HP - Hôpital Pitié-Salpêtrière, Paris, France. ${ }^{31}$ Département de Neurologie, AP-HP - Hôpital Pitié-Salpêtrière, Paris, France. ${ }^{32}$ University of Lille, Lille, France. ${ }^{33}$ Inserm 1172, Lille, France. ${ }^{34} \mathrm{CHU}$, CNR-MAJ, Labex Distalz, LiCEND, Lille, France.

Received: 7 September 2021 Accepted: 28 December 2021

Published online: 19 January 2022

\section{References}

1. Seelaar H, Rohrer JD, Pijnenburg YA, Fox NC, van Swieten JC. Clinical, genetic and pathological heterogeneity of frontotemporal dementia: a review. J Neurol Neurosurg Psychiatry. 2011;82(5):476-86.

2. Rascovsky K, Hodges JR, Knopman D, Mendez MF, Kramer JH, Neuhaus J, et al. Sensitivity of revised diagnostic criteria for the behavioural variant of frontotemporal dementia. Brain. 2011;134(Pt 9):2456-77.

3. Gorno-Tempini ML, Hillis AE, Weintraub S, Kertesz A, Mendez M, Cappa SF, et al. Classification of primary progressive aphasia and its variants. Neurology. 2011;76(11):1006-14.

4. Lashley T, Rohrer JD, Mead S, Revesz T. An update on clinical, genetic and pathological aspects of frontotemporal lobar degenerations. Neuropathol Appl Neurobiol. 2015;41(7):858-81.

5. Desmarais P, Rohrer JD, Nguyen QD, Herrmann N, Stuss DT, Lang AE, et al. Therapeutic trial design for frontotemporal dementia and related disorders. J Neurol Neurosurg Psychiatry. 2019;90(4):412-23.

6. Tsai RM, Boxer AL. Therapy and clinical trials in frontotemporal dementia: past, present, and future. J Neurochem. 2016;138:211-21.

7. Panza F, Lozupone M, Seripa D, Daniele A, Watling M, Giannelli G, et al. Development of disease-modifying drugs for frontotemporal dementia spectrum disorders. Nat Rev Neurol. 2020;16(4):213-28.

8. Langbaum JB, Hendrix SB, Ayutyanont N, Chen K, Fleisher AS, Shah $\mathrm{RC}$, et al. An empirically derived composite cognitive test score with improved power to track and evaluate treatments for preclinical Alzheimer's disease. Alzheimers Dement. 2014;10(6):666-74.

9. Silverberg NB, Ryan LM, Carrillo MC, Sperling R, Petersen RC, Posner HB, et al. Assessment of cognition in early dementia. Alzheimers Dement. 2011;7(3):e60-76.

10. Cano SJ, Posner HB, Moline ML, Hurt SW, Swartz J, Hsu T, et al. The ADAScog in Alzheimer's disease clinical trials: psychometric evaluation of the sum and its parts. J Neurol Neurosurg Psychiatry. 2010;81(12):1363-8.

11. Rosen WG, Mohs RC, Davis KL. A new rating scale for Alzheimer's disease. Am J Psychiatry. 1984;141(11):1356-64.

12. Jiskoot LC, Dopper EG, Heijer T, Timman R, van Minkelen R, van Swieten $J$, et al. Presymptomatic cognitive decline in familial frontotemporal dementia: a longitudinal study. Neurology. 2016;87(4):384-91.

13. Jiskoot LC, Panman JL, Meeter LH, Dopper EGP, Donker Kaat L, Franzen $\mathrm{S}$, et al. Longitudinal multimodal MRI as prognostic and diagnostic biomarker in presymptomatic familial frontotemporal dementia. Brain. 2018;142(1):193-208.

14. Rohrer JD, Nicholas JM, Cash DM, van Swieten J, Dopper E, Jiskoot L, et al. Presymptomatic cognitive and neuroanatomical changes in genetic frontotemporal dementia in the Genetic Frontotemporal dementia Initiative (GENFI) study: a cross-sectional analysis. Lancet Neurol. 2015;14(3):253-62.

15. Barandiaran M, Estanga A, Moreno F, Indakoetxea B, Alzualde A, Balluerka $\mathrm{N}$, et al. Neuropsychological features of asymptomatic c. 709-1G> A progranulin mutation carriers. J Int Neuropsychol Soc. 2012;18(6):1086-90.

16. Bertrand A, Wen J, Rinaldi D, Houot M, Sayah S, Camuzat A, et al. Early cognitive, structural, and microstructural changes in presymptomatic C9orf72 carriers younger than 40 years. JAMA Neurol. 2018;75(2):236-45.

17. Floeter MK, Traynor BJ, Farren J, Braun LE, Tierney M, Wiggs EA, et al. Disease progression in C9orf72 mutation carriers. Neurology. 2017;89(3):234-41.

18. Hallam BJ, Jacova C, Hsiung G-YR, Wittenberg D, Sengdy P, Bouchard-Kerr $P$, et al. Early neuropsychological characteristics of progranulin mutation carriers. Journal of the International Neuropsychological Society. JINS. 2014;20(7):694. 
19. Staffaroni AM, Bajorek L, Casaletto KB, Cobigo Y, Goh SYM, Wolf A, et al. Assessment of executive function declines in presymptomatic and mildly symptomatic familial frontotemporal dementia: NIH-EXAMINER as a potential clinical trial endpoint. Alzheimers Dement. 2020;16(1):11-21.

20. Poos JM, Russell LL, Peakman G, Bocchetta M, Greaves CV, Jiskoot LC, et al. Impairment of episodic memory in genetic frontotemporal dementia: a GENFI study. Alzheimer's Dement Diagn Assess Dis Monit. 2021;13(1):e12185.

21. Barandiaran M, Moreno F, de Arriba M, Indakoetxea B, Boda I, Gabilondo A, et al. Longitudinal neuropsychological study of presymptomatic c. 709-1G> A progranulin mutation carriers. J Int Neuropsychol Soc. 2019;25(1):39-47.

22. Poos JM, Jiskoot LC, Leijdesdorff SMJ, Seelaar H, Panman JL, van der Ende $E L$, et al. Cognitive profiles discriminate between genetic variants of behavioral frontotemporal dementia. J Neurol. 2020;267(6):1603-12.

23. Le Ber I, Camuzat A, Hannequin D, Pasquier F, Guedj E, RoveletLecrux A, et al. Phenotype variability in progranulin mutation carriers: a clinical, neuropsychological, imaging and genetic study. Brain 2008;131(3):732-46.

24. Cheran G, Wu L, Lee S, Manoochehri M, Cines S, Fallon E, et al. Cognitive indicators of preclinical behavioral variant frontotemporal dementia in MAPT carriers. J Int Neuropsychol Soc. 2019;25(2):184-94.

25. Geschwind DH, Robidoux J, Alarcón M, Miller BL, Wilhelmsen KC, Cummings $J$, et al. Dementia and neurodevelopmental predisposition: cognitive dysfunction in presymptomatic subjects precedes dementia by decades in frontotemporal dementia. Ann Neurol. 2001;50(6):741-6.

26. Papma JM, Jiskoot LC, Panman JL, Dopper EG, Den Heijer T, Kaat LD, et al. Cognition and gray and white matter characteristics of presymptomatic C9orf72 repeat expansion. Neurology. 2017;89(12):1256-64.

27. Jiskoot LC, Panman JL, van Asseldonk L, Franzen S, Meeter LHH, Kaat LD, et al. Longitudinal cognitive biomarkers predicting symptom onset in presymptomatic frontotemporal dementia. J Neurol. 2018;265(6):1381-92.

28. Tsoy E, Erlhoff SJ, Goode CA, Dorsman KA, Kanjanapong S, Lindbergh CA, et al. BHA-CS: a novel cognitive composite for Alzheimer's disease and related disorders. Alzheimer's Dement Diagn Assess Dis Monit. 2020;12(1):e12042.

29. Jones R, Stout JC, Labuschagne I, Say M, Justo D, Coleman A, et al. The potential of composite cognitive scores for tracking progression in Huntington's disease. J Huntington's Dis. 2014;3(2):197-207.

30. Fahn S. Unified Parkinson's disease rating scale. Recent development in Parkinson's disease; 1987.

31. Miyagawa T, Brushaber D, Syrjanen J, Kremers W, Fields J, Forsberg LK, et al. Utility of the global CDR ${ }^{\circledR}$ plus NACC FTLD rating and development of scoring rules: data from the ARTFL/LEFFTDS Consortium. Alzheimers Dement. 2020;16(1):106-17.

32. Brooks BR, Miller RG, Swash M, Munsat TL. El Escorial revisited: revised criteria for the diagnosis of amyotrophic lateral sclerosis. Amyotroph Later Scleros Motor Neuron Disord. 2000;1 (5):293-9.

33. Moore K, Convery R, Bocchetta M, Neason M, Cash DM, Greaves C, et al. A modified Camel and Cactus Test detects presymptomatic semantic impairment in genetic frontotemporal dementia within the GENFI cohort. Appl Neuropsychol Adult. 2020:1-8. Ahead of print

34. Morris JC, Weintraub S, Chui HC, Cummings J, DeCarli C, Ferris S, et al. The Uniform Data Set (UDS): clinical and cognitive variables and descriptive data from Alzheimer disease centers. Alzheimer Dis Assoc Disord. 2006;20(4):210-6.

35. Tombaugh TN, Kozak J, Rees L. Normative data stratified by age and education for two measures of verbal fluency: FAS and animal naming. Arch Clin Neuropsychol. 1999;14(2):167-77.

36. Corrigan JD, Hinkeldey NS. Relationships between parts A and B of the Trail Making Test. J Clin Psychol. 1987;43(4):402-9.

37. Delis DC, Kaplan E, Kramer J, den Buysch HO, Noens ILJ, Berckelaer-Onnes IA. D-KEFS: Delis-Kaplan executive function system: color-word interference test: handleiding. Amsterdam: Pearson; 2008.

38. Russell LL, Greaves CV, Bocchetta M, Nicholas J, Convery RS, Moore K, et al. Social cognition impairment in genetic frontotemporal dementia within the GENFI cohort. Cortex. 2020.

39. Folstein MF, Folstein SE, McHugh PR. "Mini-mental state": a practical method for grading the cognitive state of patients for the clinician. J Psychiatr Res. 1975;12(3):189-98.
40. Kukreja SL, Löfberg J, Brenner MJ. A least absolute shrinkage and selection operator (LASSO) for nonlinear system identification. IFAC Proc. 2006;39(1):814-9.

41. Friedman LM, Furberg C, DeMets DL. Fundamentals of clinical trials. 5th ed. New York: Springer; 2015. Print

42. Coyle-Gilchrist ITS, Dick KM, Patterson K, Rodríquez PV, Wehmann E, Wilcox A, et al. Prevalence, characteristics, and survival of frontotemporal lobar degeneration syndromes. Neurology. 2016;86(18):1736-43.

43. Mahoney CJ, Downey LE, Ridgway GR, Beck J, Clegg S, Blair M, et al. Longitudinal neuroimaging and neuropsychological profiles of frontotemporal dementia with C9ORF72 expansions. Alzheimers Res Ther. 2012;4(5):41.

44. Rohrer JD, Warren JD. Phenotypic signatures of genetic frontotemporal dementia. Curr Opin Neurol. 2011;24(6):542-9.

45. Boeve B, Bove J, Brannelly P, Brushaber D, Coppola G, Dever R, et al. The longitudinal evaluation of familial frontotemporal dementia subjects protocol: framework and methodology. Alzheimers Dement. 2019.

\section{Publisher's Note}

Springer Nature remains neutral with regard to jurisdictional claims in published maps and institutional affiliations.
Ready to submit your research? Choose BMC and benefit from:

- fast, convenient online submission

- thorough peer review by experienced researchers in your field

- rapid publication on acceptance

- support for research data, including large and complex data types

- gold Open Access which fosters wider collaboration and increased citations

- maximum visibility for your research: over 100M website views per year

At BMC, research is always in progress.

Learn more biomedcentral.com/submissions 